This is an electronic reprint of the original article. This reprint may differ from the original in pagination and typographic detail.

\author{
Author(s): Laulainen, Janne; Aleiferis, S.; Kalvas, Taneli; Koivisto, Hannu; Kronholm, Risto; \\ Tarvainen, Olli
}

Title: Hydrogen plasma induced photoelectron emission from low work function cesium covered metal surfaces

Year: $\quad 2017$

Version:

Please cite the original version:

Laulainen, J., Aleiferis, S., Kalvas, T., Koivisto, H., Kronholm, R., \& Tarvainen, O.

(2017). Hydrogen plasma induced photoelectron emission from low work function cesium covered metal surfaces. Physics of Plasmas, 24(10), Article 103502.

https://doi.org/10.1063/1.4998005

All material supplied via JYX is protected by copyright and other intellectual property rights, and duplication or sale of all or part of any of the repository collections is not permitted, except that material may be duplicated by you for your research use or educational purposes in electronic or print form. You must obtain permission for any other use. Electronic or print copies may not be offered, whether for sale or otherwise to anyone who is not an authorised user. 


\section{Hydrogen plasma induced photoelectron emission from low work function cesium covered metal surfaces}

J. Laulainen, S. Aleiferis, T. Kalvas, H. Koivisto, R. Kronholm, and O. Tarvainen

Citation: Physics of Plasmas 24, 103502 (2017); doi: 10.1063/1.4998005

View online: http://dx.doi.org/10.1063/1.4998005

View Table of Contents: http://aip.scitation.org/toc/php/24/10

Published by the American Institute of Physics

\section{Articles you may be interested in}

VUV emission spectroscopy combined with $\mathrm{H}^{-}$density measurements in the ion source Prometheus I

AIP Conference Proceedings 1869, 030045 (2017); 10.1063/1.4995765

Photoelectron emission experiments with ECR-driven multi-dipolar negative ion plasma source AIP Conference Proceedings 1869, 020012 (2017); 10.1063/1.4995718

Detection of rovibrationally excited molecular hydrogen in the electronic ground state via synchrotron radiation Applied Physics Letters 111, 074103 (2017); 10.1063/1.4985617

Massive parallel 3D PIC simulation of negative ion extraction

Journal of Applied Physics 122, 103302 (2017); 10.1063/1.5001397

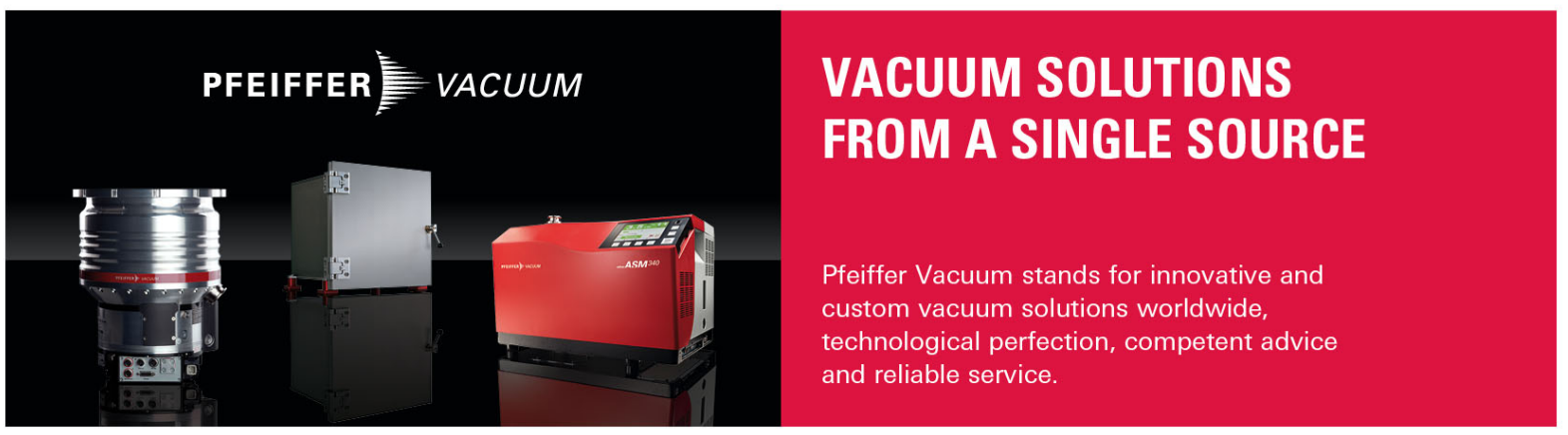




\title{
Hydrogen plasma induced photoelectron emission from low work function cesium covered metal surfaces
}

\author{
J. Laulainen, ${ }^{1, \text { a) }}$ S. Aleiferis,${ }^{2}$ T. Kalvas, ${ }^{1}$ H. Koivisto, ${ }^{1}$ R. Kronholm, ${ }^{1}$ and O. Tarvainen ${ }^{1}$ \\ ${ }^{1}$ Department of Physics, University of Jyvaskyla, Jyvaskyla, Finland \\ ${ }^{2}$ High Voltage Laboratory, Department of Electrical and Computer Engineering, University of Patras, \\ Rion-Patras 26504, Greece
}

(Received 28 July 2017; accepted 27 August 2017; published online 14 September 2017)

\begin{abstract}
Experimental results of hydrogen plasma induced photoelectron emission from cesium covered metal surfaces under ion source relevant conditions are reported. The transient photoelectron current during the $\mathrm{Cs}$ deposition process is measured from $\mathrm{Mo}, \mathrm{Al}, \mathrm{Cu}, \mathrm{Ta}, \mathrm{Y}, \mathrm{Ni}$, and stainless steel (SAE 304) surfaces. The photoelectron emission is 2-3.5 times higher at optimal Cs layer thickness in comparison to the clean substrate material. Emission from the thick layer of $\mathrm{Cs}$ is found to be $60 \%-80 \%$ lower than the emission from clean substrates. Published by AIP Publishing. [http://dx.doi.org/10.1063/1.4998005]
\end{abstract}

\section{INTRODUCTION}

Negative hydrogen and deuterium ion sources are used in many applications, for example, neutral beam injection into fusion devices, ${ }^{1}$ charge exchange injection into storage rings, e.g., in spallation neutron sources ${ }^{2}$ and isotope production with cyclotrons. ${ }^{3} \mathrm{H}^{-} / \mathrm{D}^{-}$ions are produced via two predominant channels, dissociative electron attachment in the plasma volume and the surface production. ${ }^{4}$ Surface production of negative hydrogen ions is based on electron tunneling from the conduction band of a metal to the affinity level of a hydrogen atom. ${ }^{5}$ Cesium is commonly used in negative ion sources to enhance the surface production of negative ions by lowering the work function and thereby increasing the tunneling probability. ${ }^{6-8}$ However, lowering the work function can also enhance the photoelectron (PE) emission induced by the plasma light emission, the effect of which has not been studied as extensively.

Theoretical calculations based on fundamental conservation laws and reaction cross sections show that at least $10 \%$ of plasma heating power is dissipated via photon emission in low temperature hydrogen plasmas. ${ }^{9}$ The theoretical result is supported by experimental evidence showing that low temperature hydrogen plasmas are strong sources of vacuum ultraviolet (VUV) radiation with up to $15 \%-30 \%$ of the discharge power radiated at wavelengths of $120-250 \mathrm{~nm}$ in filamentdriven arc discharge, ${ }^{10}$ up to $8 \%$ of the injected microwave power at $80-250 \mathrm{~nm}$ in ECR discharge, ${ }^{11}$ and up to $21 \%$ of RF power at $117-280 \mathrm{~nm}$ in RF discharge. ${ }^{12}$

Electrons in the conduction band of a metal follow the Fermi-Dirac distribution which can be used to derive the following relation for the quantum efficiency $Y$ of the PE emission: ${ }^{13}$

$$
\begin{aligned}
Y & \propto \frac{(h \nu-\phi)^{2}}{\left(U_{0}-h \nu\right)^{1 / 2}}, & & \text { when } h \nu \geq \phi, \\
& =0, & & \text { when } h \nu<\phi,
\end{aligned}
$$

\footnotetext{
a) janne.p.laulainen@student.jyu.fi
}

where $h \nu$ is the energy of the photon, $\phi$ is the work function, and $U_{0}$ is the potential step at the surface-vacuum boundary. However, this relationship is accurate only for photon energies near the threshold, when electrons are emitted close to the surface and the quantum efficiency is not affected by the electron transport inside the metal lattice. Typical work functions of common metals are on the order of $4-5 \mathrm{eV}$. Adsorption of electropositive $\mathrm{Cs}$ atoms on a metal surface takes place by transfer of a valence electron to the conduction band of the metal. ${ }^{14}$ As the Cs coverage on the surface increases, the work function decreases reaching a minimum value at $0.5-0.7$ monolayer thickness. Beyond this, repulsive forces between dipole bonds lead to an increasing work function saturating to a value corresponding to bulk Cs at one monolayer thickness. An area density of $5.5 \times 10^{14} \mathrm{Cs}$ atoms per $\mathrm{cm}^{2}$ corresponds to one monolayer. ${ }^{15}$ The minimum work function $\phi_{\min }$ of a cesiated metal surface can be estimated using a semiempirical expression ${ }^{14}$

$$
\phi_{\min }=2.707-0.24 \phi_{0},
$$

where $\phi_{0}$ is the work function of uncesiated metal. Higher $\phi_{0}$ results to lower $\phi_{\min }$, which is due to stronger electric field on the surface. The functional dependence of the work function on surface coverage $\theta$ can be estimated using a semiempirical expression $^{14}$

$$
\begin{aligned}
\phi(\theta) \simeq & \phi_{0}+\frac{6 \Delta \phi_{\min }}{\left(3-\theta_{\min }\right) \theta_{\min }} \theta-\frac{3 \Delta \phi_{\min }\left(\theta_{\min }+1\right)}{\left(3-\theta_{\min }\right) \theta_{\min }^{2}} \theta^{2} \\
& +\frac{2 \Delta \phi_{\min }}{\left(3-\theta_{\min }\right) \theta_{\min }^{2}} \theta^{3}
\end{aligned}
$$

where $\Delta \phi=\phi_{\min }-\phi_{0}$ is the work function change and $\theta_{\min }$ is the relative coverage corresponding to the minimum work function. Work function values suggested by Eq. (3), which have been shown to be in good accuracy with experimental data, ${ }^{14}$ are plotted in Fig. 1 for different substrates (used in the experiments) with variable $\phi_{0}{ }^{16,17}$ with a choice of $\theta_{\text {min }}$ $=0.5$. 


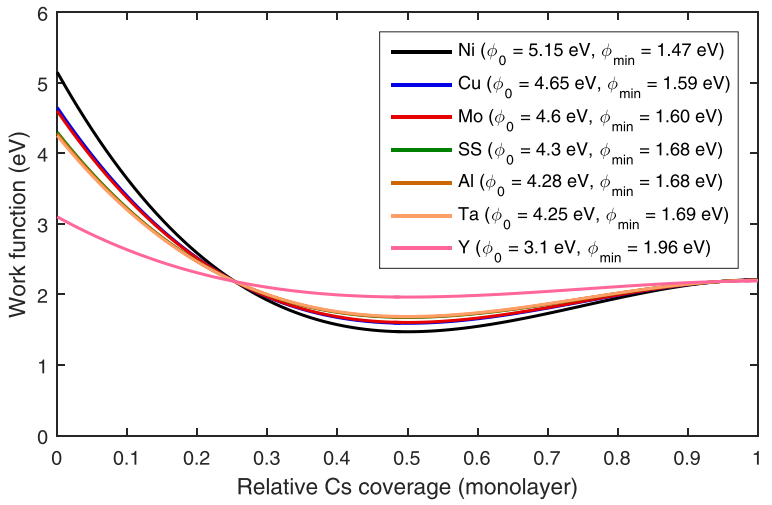

FIG. 1. Semiempirical relationship for the work function as a function of relative Cs coverage in monolayers on different substrates.

Quantified values for the work function of Cs covered metals are usually measured in ultra-high vacuum conditions. ${ }^{17-20}$ However, in ion sources the surface is unavoidably exposed to higher neutral particle fluxes, plasma bombardment, and UV radiation which can affect the formation of the Cs layer. Furthermore, the high reactivity of Cs leads to formation of compounds, e.g., $\mathrm{CsOH}$ and $\mathrm{Cs}_{2} \mathrm{O}$, with the impurities present in all low temperature ion source plasmas. The thickness of the Cs layer and the level of surface impurities are determined by the balance between their deposition and adsorption rates. Hence, the surface conditions can have significant temporal variation especially in pulsed high power discharges. ${ }^{21,22}$ Usually a continuous evaporation of Cs into the source is used to keep the surfaces "clean." $23-25$ There are experimental results from a Penning type ion source showing notable transient lines of Cs compounds in the VUV spectra after plasma ignition. ${ }^{26}$ It has been suggested that the involvement of Cs compounds in the Cs dynamics of the ion source is significant or even dominating in ion sources for neutral beam injection. ${ }^{23}$ Therefore, work function values derived from the measurements performed at ultra-high vacuum conditions do not apply directly to ion sources, and the minimum work function measured under ion source relevant conditions is typically higher. ${ }^{27}$ However, a work function of less than $1.91 \mathrm{eV}$, which is below the work function of solid Cs, has been measured with a $650 \mathrm{~nm}$ laser from a negative ion source converter surface. ${ }^{28}$
As the work function decreases with the build-up of the Cs layer, the PE quantum efficiency increases, since a wider range of hydrogen VUV emission spectrum is able to induce $\mathrm{PE}$ emission. Thus, an increase in the PE emission is expected with a buildup of a thin Cs layer. It has been shown that low temperature hydrogen plasma induced PE emission from clean metals is predominantly caused by radiation at wavelengths shorter than $150 \mathrm{~nm},{ }^{29}$ i.e., Lyman-alpha $(121.6 \mathrm{~nm})$ and Werner-band $(84-158 \mathrm{~nm})$ emission, which is due to the wavelength dependence of the quantum efficiency first increasing towards shorter wavelengths and then decreasing at wavelengths below $50 \mathrm{~nm} .{ }^{30}$ The Lyman-alpha and Werner-band range have also been found to dominate the plasma emission spectral power in the filament-driven arc discharge. ${ }^{10} \mathrm{It}$ is not known how Cs deposition on a metal surface affects the quantum efficiency at this wavelength range, which motivates to study how hydrogen plasma induced PE emission is affected by the Cs deposition. The objective of the experiment is to quantify the change in hydrogen plasma induced PE emission as a function of the Cs coverage of a metal surface in ion source relevant conditions.

\section{EXPERIMENTAL SETUP}

The experimental setup is presented in Fig. 2. The measurements were performed with a filament-driven multi-cusp arc discharge plasma generator, which is a commonly used technology in volume production $\mathrm{H}^{-}$ion sources, e.g., LIISA $\mathrm{H}^{-}$ion source at JYFL. ${ }^{31}$ The vacuum chamber is evacuated down to $10^{-8}$ mbar background pressure with a $880 \mathrm{ls}^{-1}$ turbomolecular pump before introducing $99.9999 \%$ purity hydrogen into the discharge volume. $70 \mathrm{~V} / 4 \mathrm{~A}$ arc discharge voltage/current ( $280 \mathrm{~W}$ discharge power) and a plasma chamber (hydrogen) pressure of $2 \times 10^{-2}$ mbar were used in the measurements. It has been shown earlier that the PE current measured from clean metal samples increases linearly with the discharge power. ${ }^{29}$ A VUV emission spectrum measured from the hydrogen plasma with a spectrometer consisting of a monochromator (McPherson model 234/302), holographic grating, and photomultiplier tube (ET Enterprises 9406B) is presented in Fig. 3.

The PE emission is measured from a remote sample, which is illuminated by light emitted from the arc discharge.

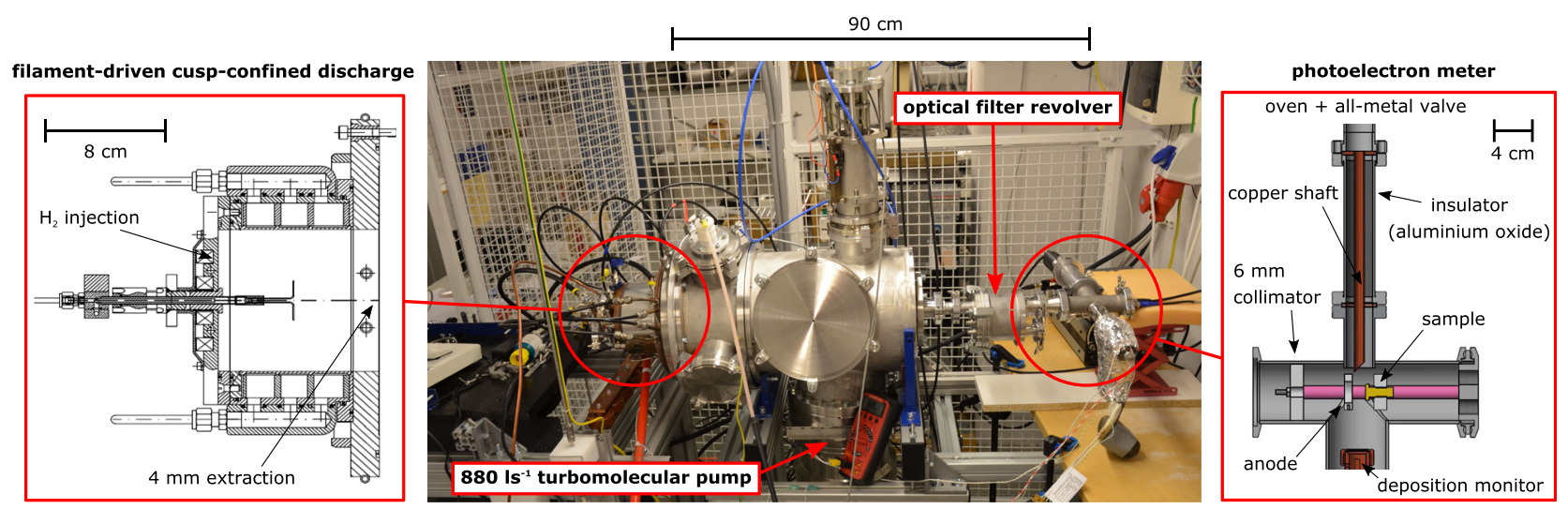

FIG. 2. The experimental setup with cross-sectional views of the plasma generator and the photoelectron meter. 


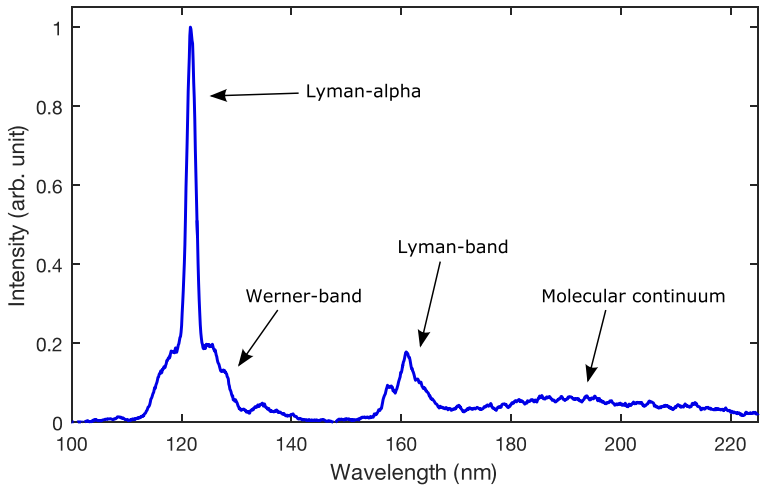

FIG. 3. VUV emission spectrum of the hydrogen plasma generator. The spectrum is not calibrated for spectral response.

It is not possible to measure the PE emission inside the plasma chamber, because the measured current would be affected by particle currents from various sources (plasma losses, secondary electron emission, etc.) making it impossible to determine the origin of electrons in the plasma. The PE current was measured with an updated version of a previous apparatus ${ }^{29}$ with an integrated Cs oven and a deposition monitor. The light emitted by the hydrogen plasma passes through the extraction aperture $(\varnothing 4 \mathrm{~mm})$ of the plasma chamber and travels through the collimator $(\varnothing 6 \mathrm{~mm})$ and illuminates the sample $(4 \mathrm{~cm}$ behind the collimator, $90 \mathrm{~cm}$ away from the plasma generator). The PE current is measured from the sample with a SRS SR570 preamplifier and National Instruments data acquisition system. The emitted electrons are collected with an anode ring located approximately $10 \mathrm{~mm}$ from the target and biased to $+150 \mathrm{~V}$ with respect to the grounded cathode. The vacuum system includes an optical filter revolver that can be used to limit the wavelength range incident on the sample. A bandpass filter corresponding to Lyman-alpha (eSource Optics 25122FNB, $122 \mathrm{~nm}$, FWHM 20nm) was used to study the predominant part of the spectrum for PE emission. The transmittance of the filter is in the order of a few percent. The photons are impinging on the macroscopic sample surface on normal incidence. The angle of incidence does not affect the measured PE current since the peak-topeak roughness of the sample surface is over $100 \mathrm{~nm}$, which exceeds the mean free path for VUV photons and the escape depth of the PEs and, therefore, effectively randomizes the photon angle of incidence in the microscale. ${ }^{32}$ It is not possible to estimate reliably the molecular/atomic hydrogen flux reaching the sample due to the gas feed and pumping arrangement. The sample temperature can be considered to be close to the ambient temperature. The sample is mechanically and chemically cleaned before the measurements. Metals chosen for substrate materials are typically used in negative hydrogen ion sources as chamber materials $[\mathrm{Al}, \mathrm{Cu}$, stainless steel (SS),$^{33-35}$ filament materials (Ta), ${ }^{31,36}$ plasma grid materials $(\mathrm{Mo})^{37}$ or so-called collar materials (SS, Mo). ${ }^{38,39}$ Also Ni and $\mathrm{Y}$ were chosen as high and low work function materials, respectively.

The Cs oven is based on the Los Alamos design. ${ }^{21} \mathrm{Cs}$ is evaporated from the oven consisting of a flexible bellows, where the $1 \mathrm{~g} \mathrm{Cs}$ ampoule is placed and broken inside the vacuum by bending the bellows, and an all-metal valve. The oven is connected to the vacuum system with a thermal insulator and Cs is supplied through a copper shaft. The oven is heated up to $200^{\circ} \mathrm{C}$ and kept at a constant temperature as $\mathrm{Cs}$ evaporates onto the metal sample in the PE detector. An Inficon XTM/2 deposition monitor, placed next to the sample, was used to verify the accumulation of $\mathrm{Cs}$, but absolute layer thickness on the sample was not measured.

\section{RESULTS AND DISCUSSION}

Figure 4 presents the PE current measured from the Mo sample while $\mathrm{Cs}$ is deposited on the sample surface. As Cs starts to evaporate, a significant increase in the PE current is observed. As the thickness of the Cs coverage grows, the PE current exhibits a double hump structure before starting to decrease. The PE current eventually saturates to a value, lower than the signal from a clean substrate that corresponds to bulk Cs. The PE current measured with the Lyman-alpha filter shows similar behavior as a function of Cs coverage on the substrate compared to the current measured without a filter.

The observations can be qualitatively explained by the decreasing work function of the surface, and by comparison of the photon penetration depth within the Cs layer and the metal substrate to the escape depth of the PEs. It is clearly noticeable that the work function change, illustrated in Fig. 1, alone does not explain the observed behavior of the PE emission. The mean free path for $10 \mathrm{eV}$ VUV photons, which is the average energy for the predominant part of the spectrum, is $10 \mathrm{~nm}$ in Mo while the penetration depth in Cs is $13 \mu \mathrm{m} .{ }^{40}$ This means that photons interact predominantly with the Mo substrate even at a considerable Cs layer thickness. With a thin layer of Cs, the work function is lowered and thus the PE yield is higher, as long as the emitted electrons are able to propagate through the Cs layer with sufficient energy. Typical escape depth of PEs with energies of a few eV is $1-3 \mathrm{~nm}^{41}$ If the Cs layer is too thick, the PE current is limited by the short escape depth of the electrons, although the work function is lower for bulk Cs in comparison to Mo. The weaker PE emission from bulk Cs compared

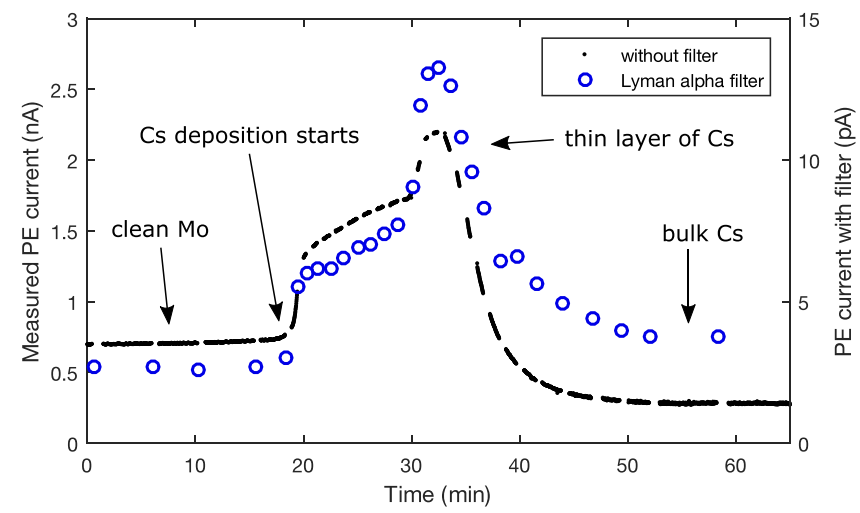

FIG. 4. Measured photoelectron current from the Mo sample as a function of time (i.e., Cs coverage on the surface) by exposing the sample to the whole emission spectrum of the hydrogen plasma (left axis) and by applying the Lyman-alpha filter (right axis). Gaps in the data correspond to filtered measurements. 
to clean Mo can be attributed to at least two factors. One is the long mean free path of photons in Cs versus the short escape depth of PEs and the other is the lower density of conduction band electrons in $\mathrm{Cs}$ (Fermi energy $1.59 \mathrm{eV}^{42}$ ) in comparison to Mo (Fermi energy $5.32 \mathrm{eV}^{43}$ ) It was confirmed with the deposition monitor that the observed transition was indeed caused by a thin layer of $\mathrm{Cs}$, since a change in the PE signal was observed before measuring any detectable signal with the deposition monitor, which has a resolution of $0.01 \mathrm{~nm}$. The measurements are repeatable with less than $12 \%$ variation in the maximum gain with optimal Cs layer thickness as measured with $\mathrm{Mo}$ and $\mathrm{Al}$ samples in four independent measurements per sample. The repeatability includes variable evaporation rates, which presumably affects the concentration of Cs compounds on the sample surface. Uneven Cs distribution on the substrate can create patches with different PE quantum efficiency causing nonhomogeneity of the PE emission. ${ }^{44,45}$ These patches can be caused by local nonuniformity of the substrate due to different crystal faces, roughness, contamination, etc. However, the characteristic dimension of the irradiated surface area $(\varnothing 6 \mathrm{~mm})$ is much larger than the surface roughness (peakto-peak over $100 \mathrm{~nm}$ ) and the dimensions of the possible patches. Thus, it can be expected that the patch effect is averaged over multiple measurements and included in the uncertainty probed by repeated measurements.

Figure 5 presents the measured absolute PE currents from different substrates [Mo, Al, Cu, Ta, SS (SAE 304), Y, and $\mathrm{Ni}$ ] as $\mathrm{Cs}$ is deposited on the surface. The horizontal axes have been normalized with the $\mathrm{Cs}$ deposition rate for easier comparison, because even a small change in the oven temperature has a significant impact on the deposition rate. Clean substrate materials have variable work functions in the range of $3.1-5.15 \mathrm{eV},{ }^{16,17}$ while the mean free path for $10 \mathrm{eV}$ VUV photons varies in the range of $8-13 \mathrm{~nm} .{ }^{40}$ The observed behavior in the PE current transition is similar for all the substrate materials. The PE current is 2-3.5 times higher at optimal Cs layer thickness compared to the clean substrate material. Y has the lowest work function of all the substrates $(3.1 \mathrm{eV})$ and, thus, has the smallest change in the work function due to Cs deposition as suggested by Eq. (2). Y also has the smallest increase in PE current by $\mathrm{Cs}$ deposition. Ni,
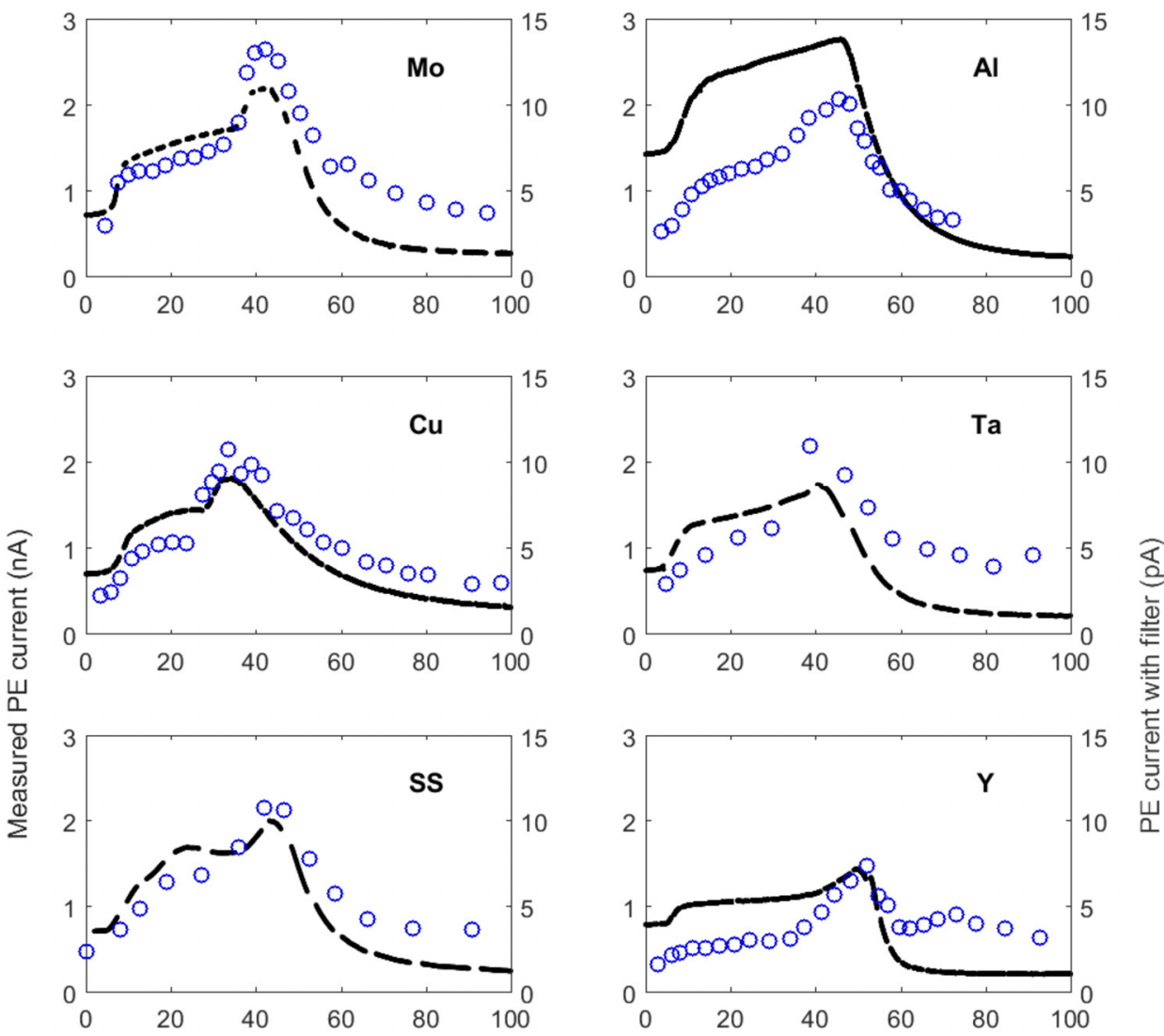

FIG. 5. Measured photoelectron currents from different substrates as a function of Cs coverage by exposing the sample to the whole emission spectrum of the hydrogen plasma (left axes) and by applying the Lymanalpha filter (right axes).

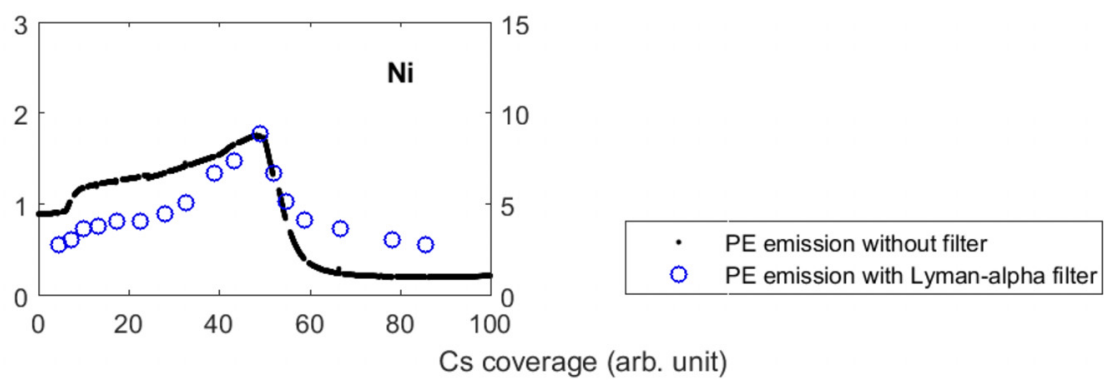



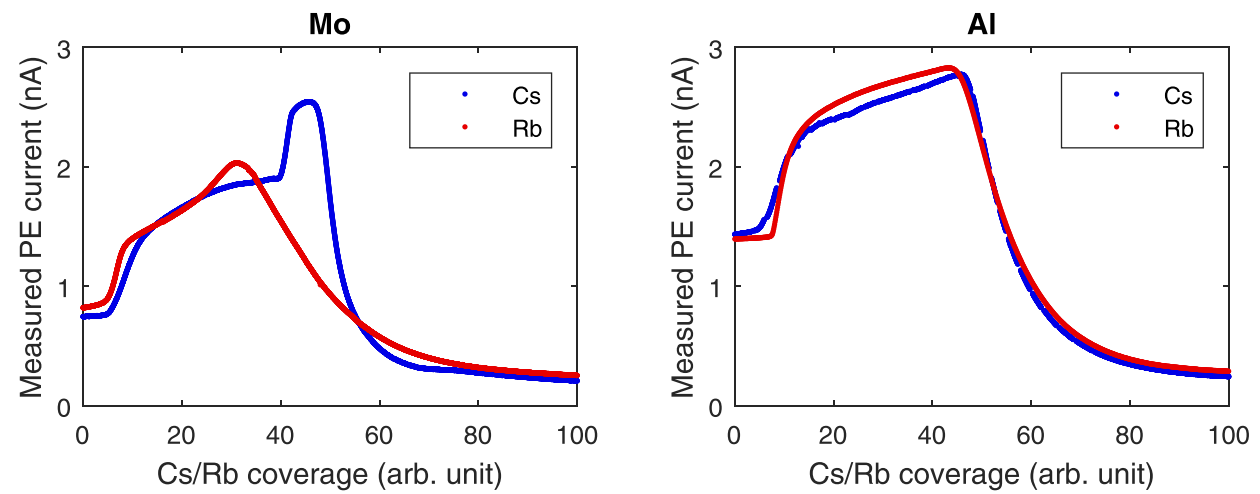

FIG. 6. Measured photoelectron currents from $\mathrm{Mo}$ and $\mathrm{Al}$ substrates as a function of $\mathrm{Cs}$ and $\mathrm{Rb}$ coverage. which has the highest work function $(5.15 \mathrm{eV})$, behaves similar to the other substrate materials, which have work functions between 4 and $5 \mathrm{eV}$. With all the substrates the PE current saturates to the same value, which is $60 \%-80 \%$ lower than the starting value, supporting the conclusion that the emission is from bulk Cs. The relative difference in the PE current measured with the Lyman-alpha filter in proportion to the PE current measured without a filter has somewhat different values for different metals. The ratio also changes as a function of the Cs coverage. This is believed to be due to the functional dependence of the PE emission quantum efficiency on the photon energy with varying work function. ${ }^{30,46}$

$\mathrm{Rb}$ was used as an alternative alkali metal to confirm the results obtained with $\mathrm{Cs}$. The work function of $\mathrm{Rb}(2.16 \mathrm{eV})$ is almost as low as the work function of $\mathrm{Cs}(2.14 \mathrm{eV}) .{ }^{16} \mathrm{~A}$ comparison of $\mathrm{PE}$ emission from $\mathrm{Mo}$ and $\mathrm{Al}$ substrates as a function of $\mathrm{Cs}$ and $\mathrm{Rb}$ coverage is presented in Fig. 6. In four independent measurements for both alkali metals on Mo substrate, the increase factor in PE current from the clean substrate to maximum current was 3.4 for $\mathrm{Cs}$ and 2.6 for $\mathrm{Rb}$ on average. Based on two independent measurements with $\mathrm{Rb}$ on $\mathrm{Al}$, it is concluded that the $\mathrm{PE}$ emission from $\mathrm{Rb}$ covered $\mathrm{Al}$ is practically the same as for $\mathrm{Cs}$ covered $\mathrm{Al}$. The PE current saturates to the same value with both alkali metals, i.e., low temperature hydrogen plasma induced PE emission from bulk $\mathrm{Cs}$ and bulk $\mathrm{Rb}$ are identical. The comparison of the two alkali metals also suggests that their impurity compounds with different chemical properties play a minor role in determining the PE current.

The role of PEs in plasmas is not well known as they might have a considerable effect on various plasma processes depending on the intensity and the energy distribution of the emitted electrons. In addition to the energy of the absorbed photon, the final energy distribution of the emitted electrons is determined by the plasma sheath structure, i.e., (positive) plasma potential and a possible virtual cathode. A virtual cathode can be formed, if the emission of electrons (and negative ions) from the wall is high enough to prevent the compensation of the space charge by incoming positive ions. $^{47,48}$ If the virtual cathode exists, it limits the transport of the low energy PEs to the plasma, but does not change the energy of the PEs that reach the plasma as the sheath potential forms between the conducting chamber wall and bulk plasma. The emitted electrons may have an impact on the volumetric rates of the dissociative electron attachment $\left(\mathrm{e}_{\text {cold }}+\mathrm{H}_{2}\left(\mathrm{X}^{1} \Sigma_{g}^{+} ; v^{\prime \prime}\right) \rightarrow \mathrm{H}_{2}^{-}\left({ }^{2} \Sigma_{u}^{+}\right) \rightarrow \mathrm{H}(1 \mathrm{~s})+\mathrm{H}^{-}\right)$which has a large cross section for vibrationally excited molecules at low electron energies (around $1 \mathrm{eV}$ ), electron detachment $\left(\mathrm{e}+\mathrm{H}^{-} \rightarrow 2 \mathrm{e}+\mathrm{H}\right)$ which has a large cross section for energies higher than $\sim 2 \mathrm{eV},{ }^{49}$ molecular excitation from the ground state to $a^{3} \Sigma_{g}^{+}$and repulsive $b^{3} \Sigma_{u}^{+}$triplet states (threshold of about 12 and $8 \mathrm{eV}$, respectively ${ }^{49}$ ) excitation from the ground state $\left(X^{1} \Sigma_{g}^{+} ; v^{\prime \prime}=0\right)$ to $B^{1} \Sigma_{u}^{+}$and $C^{1} \Pi_{u}^{+}$singlet states (threshold approximately $12 \mathrm{eV}^{50}$ ) and molecular ionization (threshold $16 \mathrm{eV}^{50}$ ). Nevertheless, processes with threshold energies higher than the difference between the energy of the absorbed photon and the surface work function are possible only if the emitted electrons with energies ranging from 0 to $h \nu-\phi$ are accelerated to sufficient energy across the plasma sheath by the plasma potential.

In the filament-driven arc discharge, the total PE current from the plasma chamber walls has been estimated to be in the order of $1 \mathrm{~A}$ per $\mathrm{kW}$ of discharge power, which corresponds to almost $10 \%$ of the arc current of $14 \mathrm{~A}$ at $70 \mathrm{~V}$ discharge voltage. ${ }^{29} \mathrm{~A}$ thin layer of alkali metal can increase the PE emission by a factor of 2-3.5 at optimal layer thickness. The results obtained in this study suggest that the PE emission especially from cesiated surfaces should be considered to be included in plasma simulations, in which the plasma surface interaction is taken into account. ${ }^{51}$ This is especially true for surface production ion sources used for neutral beam injection, in which the Cs covered multiaperture extraction grid covers a large area exposed to VUV photons. ${ }^{52,53}$ The formation of the virtual cathode requires few hundred $\mathrm{Am}^{-2}$ of negative ion current density and, due to lower space charge of electrons, it can be assumed that the PE current density needs to be higher by an order of magnitude to impact the sheath structure. Nevertheless, the effect of PEs on the plasma sheath structure may be significant for example in Penning type ion sources, ${ }^{54}$ where a few $\mathrm{kW}$ discharge power is deposited into a small plasma volume $\left(<1 \mathrm{~cm}^{3}\right)$, which can lead to high PE emission density from the walls as a significant part of the injected power is dissipated via photon emission..$^{9-12}$ On the contrary, in neutral beam injection sources the current density can be expected to be smaller, but this does not exclude the PEs effect on the reaction rates.

\section{ACKNOWLEDGMENTS}

This work has been supported by the Academy of Finland under the Finnish Centre of Excellence Programme 
2012-2017 (Nuclear and Accelerator Based Physics Research at JYFL) and the European Union's Horizon 2020 research and innovation programme under Grant Agreement No. 654002 .

${ }^{1}$ R. Hemsworth, H. Decamps, J. Graceffa, B. Schunke, M. Tanaka, M. Dremel, A. Tanga, H. P. L. De Esch, F. Geli, J. Milnes et al., Nucl. Fusion 49, 045006 (2009).

${ }^{2}$ S. Henderson, W. Abraham, A. Aleksandrov, C. Allen, J. Alonso, D. Anderson, D. Arenius, T. Arthur, S. Assadi, J. Ayers et al., Nucl. Instrum. Methods Phys. Res. A 763, 610 (2014).

${ }^{3}$ T. J. Ruth, Rep. Prog. Phys. 72, 016701 (2008).

${ }^{4}$ M. Bacal, Nucl. Fusion 46, S250 (2006).

${ }^{5}$ B. Rasser, J. N. M. van Wunnik, and J. Los, Surf. Sci. 118, 697 (1982).

${ }^{6}$ Y. I. Belchenko, G. I. Dimov, and V. G. Dudnikov, Nucl. Fusion 14, 113 (1974).

${ }^{7}$ V. G. Dudnikov, Rev. Sci. Instrum. 63, 2660 (1992).

${ }^{8}$ B. S. Lee and M. Seidl, Appl. Phys. Lett. 61, 2857 (1992).

${ }^{9}$ J. Komppula and O. Tarvainen, Phys. Plasmas 22, 103516 (2015).

${ }^{10}$ J. Komppula, O. Tarvainen, S. Lätti, T. Kalvas, H. Koivisto, V. Toivanen, and P. Myllyperkiö, AIP Conf. Proc. 1515, 66 (2013).

${ }^{11}$ J. Komppula, O. Tarvainen, T. Kalvas, H. Koivisto, R. Kronholm, J. Laulainen, and P. Myllyperkiö, J. Phys. D: Appl. Phys. 48, 365201 (2015).

${ }^{12}$ U. Fantz, S. Briefi, D. Rauner, and D. Wünderlich, Plasma Sources Sci. Technol. 25, 045006 (2016).

${ }^{13}$ R. H. Fowler, Phys. Rev. 38, 45 (1931).

${ }^{14}$ G. D. Alton, Surf. Sci. 175, 226 (1986).

${ }^{15}$ P. W. van Amersfoort, "Formation of negative ions on a metal surface," Ph.D. thesis (FOM-Institute for Atomic and Molecular Physics, Amsterdam, 1985).

${ }^{16}$ H. B. Michaelson, J. Appl. Phys. 48, 4729 (1977).

${ }^{17}$ R. G. Wilson, J. Appl. Phys. 37, 3161 (1966).

${ }^{18}$ R. G. Wilson, J. Appl. Phys. 37, 4125 (1966).

${ }^{19}$ L. W. Swanson and R. W. Strayer, J. Chem. Phys. 48, 2421 (1968).

${ }^{20}$ T. A. Callcott and A. U. Mac Rae, Phys. Rev. 178, 966 (1969).

${ }^{21}$ O. Tarvainen, Nucl. Instrum. Methods Phys. Res. A 601, 270 (2009).

${ }^{22}$ D. C. Faircloth, S. R. Lawrie, A. P. Letchford, C. Gabor, M. Whitehead, T. Wood, and M. Perkins, AIP Conf. Proc. 1390, 205 (2011).

${ }^{23} \mathrm{R}$. Friedl, "Experimental investigations on the caesium dynamics in $\mathrm{H}_{2} / \mathrm{D}_{2}$ low temperature plasmas," Ph.D. thesis (Max-Planck-Institut für Plasmaphysik (IPP), Garching, Germany, 2013).

${ }^{24}$ U. Fantz, P. Franzen, and D. Wünderlich, Chem. Phys. 398, 7 (2012).

${ }^{25}$ R. Gutser, D. Wünderlich, U. Fantz, and the N-NBI Team. Plasma Phys. Controlled Fusion 53, 105014 (2011).

${ }^{26}$ D. Faircloth, S. Lawrie, A. Letchford, C. Gabor, M. Perkins, M. Whitehead, T. Wood, O. Tarvainen, J. Komppula, T. Kalvas et al., AIP Conf. Proc. 1515, 359 (2013).

${ }^{27}$ R. Friedl and U. Fantz, AIP Conf. Proc. 1655, 020004 (2015).

${ }^{28}$ H. Yamaoka, M. Sasao, M. Wada, and H. J. Ramos, Nucl. Instrum. Methods Phys. Res. B 36, 227 (1989).
${ }^{29}$ J. Laulainen, T. Kalvas, H. Koivisto, J. Komppula, and O. Tarvainen, AIP Conf. Proc. 1655, 020007 (2015).

${ }^{30}$ B. Feuerbacher and B. Fitton, J. Appl. Phys. 43, 1563 (1972).

${ }^{31}$ T. Kuo, R. Baartman, G. Dutto, S. Hahto, J. Ärje, and E. Liukkonen, Rev. Sci. Instrum. 73, 986 (2002).

${ }^{32}$ J. Laulainen, T. Kalvas, H. Koivisto, R. Kronholm, O. Tarvainen, S. Aleiferis, and P. Svarnas, AIP Conf. Proc. 1869, 020012 (2017).

${ }^{33}$ T. Kalvas, O. Tarvainen, J. Komppula, M. Laitinen, T. Sajavaara, H. Koivisto, A. Jokinen, and M. P. Dehnel, AIP Conf. Proc. 1515, 349 (2013).

${ }^{34}$ K. R. Kendall, M. McDonald, D. R. Mosscrop, P. W. Schmor, D. Yuan, G. Dammertz, B. Piosczyk, and M. Olivo, Rev. Sci. Instrum. 57, 1277 (1986).

${ }^{35}$ C. Courteille, A. M. Bruneteau, and M. Bacal, Rev. Sci. Instrum. 66, 2533 (1995).

${ }^{36}$ T. Kuo, D. Yuan, K. Jayamanna, M. McDonald, R. Baartman, P. Schmor, and G. Dutto, Rev. Sci. Instrum. 67, 1314 (1996).

${ }^{37}$ W. Kraus, U. Fantz, P. Franzen, M. Fröschle, B. Heinemann, C. Martens, R. Riedl, and D. Wünderlich, AIP Conf. Proc. 1515, 129 (2013).

${ }^{38}$ R. F. Welton, M. P. Stockli, S. N. Murray, D. Crisp, J. Carmichael, R. H. Goulding, B. Han, O. Tarvainen, T. Pennisi, and M. Santana, AIP Conf. Proc. 1097, 181 (2009).

${ }^{39}$ Y. An, B. Jung, and Y. S. Hwang, Rev. Sci. Instrum. 81, 02 A702 (2010).

${ }^{40}$ B. L. Henke, E. M. Gullikson, and J. C. Davis, At. Data Nucl. Data Tables 54, 181 (1993).

${ }^{41}$ M. P. Seah and W. A. Dench, Surf. Interface Anal. 1, 2 (1979).

${ }^{42}$ N. W. Ashcroft and N. D. Mermin, Solid State Physics (Holt, Rinehart and Winston, 1976).

${ }^{43}$ A. Marikani, Materials Science (PHI Learning Private Limited, 2017).

${ }^{44}$ E. J. Montgomery, "Characterization of quantum efficiency and robustness of cesium-based photocathodes," Ph.D. thesis (University of Maryland, College Park, Maryland, USA, 2009).

${ }^{45}$ K. L. Jensen, P. G. O'Shea, and D. W. Feldman, Phys. Rev. ST Aceel. Beams 13, 080704 (2010).

${ }^{46}$ D. H. Dowell, F. K. King, R. E. Kirby, J. F. Schmerge, and J. M. Smedley, Phys. Rev. ST Accel. Beams 9, 063502 (2006).

${ }^{47}$ R. McAdams, D. B. King, A. J. T. Holmes, and E. Surrey, Rev. Sci. Instrum. 83, 02B109 (2012).

${ }^{48}$ H. Amemiya, B. M. Annaratone, and J. E. Allen, J. Plasma Phys. 60, 81 (1998).

${ }^{49}$ R. K. Janev, D. Reiter, and U. Samm, Collision processes in low-temperature hydrogen plasmas, Vol. Juel-4105 of Berichte des Forschungszentrums Jülich. Forschungszentrum, Zentralbibliothek, Jülich (2003).

${ }^{50}$ J.-S. Yoon, M.-Y. Song, J.-M. Han, S. H. Hwang, W.-S. Chang, and B. Lee, J. Phys. Chem. Ref. Data 37, 913 (2008).

${ }^{51}$ A. Hatayama, Rev. Sci. Instrum. 79, $02 B 901$ (2008).

${ }^{52}$ Y. Takeiri, Rev. Sci. Instrum. 81, $02 B 114$ (2010).

${ }^{53}$ B. Heinemann, H.-D. Falter, U. Fantz, P. Franzen, M. Froeschle, W. Kraus, C. Martens, R. Nocentini, R. Riedl, E. Speth, and A. Staebler, Fusion Eng. Des. 86, 768 (2011).

${ }^{54}$ D. C. Faircloth, S. Lawrie, A. P. Letchford, C. Gabor, P. Wise, M. Whitehead, T. Wood, M. Westall, D. Findlay, M. Perkins et al., Rev. Sci. Instrum. 81, 02A721 (2010). 